\title{
Left ventricular mechanical dispersion in flow-gradient patterns of severe aortic stenosis with narrow QRS complex
}

\author{
Daniel Lavall ${ }^{1} \cdot$ Linn Kristin Kuprat $^{1} \cdot$ Joscha Kandels $^{1} \cdot$ Stephan Stöbe $^{1} \cdot$ Andreas Hagendorff $^{1} \cdot$ Ulrich Laufs $^{1}$
}

Received: 4 October 2019 / Accepted: 17 December 2019 / Published online: 13 January 2020

(c) The Author(s) 2020

\begin{abstract}
Patients with severe aortic stenosis are classified according to flow-gradient patterns. We investigated whether left ventricular (LV) mechanical dispersion, a marker of dyssynchrony and predictor of mortality, is associated with low-flow status in aortic stenosis. 316 consecutive patients with aortic stenosis and QRS duration $<120 \mathrm{~ms}$ were included in the retrospective analysis. Patients with severe aortic stenosis (aortic valve area $\leq 1.0 \mathrm{~cm}^{2}$ ) were classified as normal-flow (NF; stroke volume index $\left.>35 \mathrm{ml} / \mathrm{m}^{2}\right)$ high-gradient (HG; mean transvalvular gradient $\left.\geq 40 \mathrm{mmHg}\right)(\mathrm{n}=79)$, NF low-gradient $(\mathrm{LG})(\mathrm{n}=62)$, low-flow (LF) LG ejection fraction $(E F) \geq 50 \%(n=57)$, and LF LG EF $<50 \%(n=23)$. Patients with moderate aortic stenosis (aortic valve area $1.5-1.0 \mathrm{~cm}^{2} ; \mathrm{n}=95$ ) served as comparison group. Mechanical dispersion (calculated as standard deviation of time from $\mathrm{Q} / \mathrm{S}$ onset on electrocardiogram to peak longitudinal strain in 17 left ventricular segments) was similar in patients with NF HG $(49.4 \pm 14.7 \mathrm{~ms})$, NF LG $(43.5 \pm 12.9 \mathrm{~ms}), \mathrm{LF} \mathrm{LG} \mathrm{EF} \geq 50 \%$ (47.2 $\pm 16.3 \mathrm{~ms})$ and moderate aortic stenosis $(44.2 \pm 15.7 \mathrm{~ms})$. In patients with LF LG EF $<50 \%$, mechanical dispersion was increased $(60.8 \pm 20.7 \mathrm{~ms}, \mathrm{p}<0.05$ vs. NF HG, NF LG, LF LG EF $\geq 50 \%$ and moderate AS). Mechanical dispersion correlated with global longitudinal strain $(r=0.1354, p=0.0160)$ and heart rate $(r=0.1587, p=0.0047)$, but not with parameters of aortic stenosis. Mechanical dispersion was similar among flow-gradient subgroups of severe aortic stenosis with preserved LVEF, but increased in patients with low-flow low-gradient and reduced LVEF. These findings indicate that mechanical dispersion is rather a marker of systolic myocardial dysfunction than of aortic stenosis.
\end{abstract}

Keywords Aortic stenosis $\cdot$ Low-flow $\cdot$ Strain $\cdot$ Mechanical dispersion $\cdot$ LV dysfunction

\section{Introduction}

Aortic stenosis (AS) is the most prevalent valvular heart disease in industrialized countries [1]. In patients with severe aortic stenosis, mortality increases with the onset of symptoms. Timely aortic valve (AV) replacement restores normal life expectancy [2]. Severe AS is determined by reduced aortic valve area (AVA) and increased AV pressure gradient and velocity on echocardiography $[3,4]$. However, diagnosis of severe AS can be challenging because up to $1 / 3$ of patients present with discordant findings between AV pressure gradient and AVA [5, 6]. The current guidelines recommend-after the exclusion of measurement errors-a classification into subgroups according to flow, gradient and

Daniel Lavall

Daniel.Lavall@medizin.uni-leipzig.de

1 Klinik und Poliklinik für Kardiologie, Universitätsklinikum Leipzig, Liebigstrasse 20, 04103 Leipzig, Germany left ventricular (LV) ejection fraction (EF) for therapeutic management and prognostic considerations [7, 8].

Particularly, the pathophysiology of the low-flow (stroke volume index $\leq 35 \mathrm{ml} / \mathrm{m}^{2}$ ) severe aortic stenosis is incompletely understood. Several reasons have been proposed such as pronounced $\mathrm{LV}$ concentric remodeling, impaired diastolic filling, reduced LV systolic longitudinal function, contractile dysfunction, and high afterload burden [6,9]. Speckletracking echocardiography allows detailed analysis of LV mechanics. Global longitudinal strain (GLS) has emerged as robust parameter of LV function and allows detection of subclinical LV dysfunction despite normal LVEF [10, 11]. Mechanical dispersion (MD), which is calculated as standard deviation of the time-to-peak longitudinal strain in standardized myocardial segments of the $\mathrm{LV}$, is a measure of intraventricular dyssynchrony $[12,13]$. A higher variation of the time-to-peak strain, i.e. increased mechanical dispersion, reflects heterogeneous $L V$ contraction that predicts arrhythmic risk [14] and might impair LV systolic performance. 
While complete bundle branch block causes obvious LV dyssynchrony [15], the hemodynamic impact of MD in patients with narrow QRS complex ( $\leq 120 \mathrm{~ms})$ is unknown.

We investigated whether mechanical dispersion is associated with low-flow status in aortic stenosis and narrow QRS ( $\leq 120 \mathrm{~ms}$ ) complex. LV mechanical dispersion was measured retrospectively in patients with severe aortic stenosis according to flow-gradient patterns in a large university hospital echocardiography database.

\section{Methods}

\section{Patients}

Echocardiographic data warehouse of a tertiary care hospital (Universitätsklinikum Leipzig) was screened for patients with the diagnosis "aortic stenosis" between 2013 and 2017. Consecutive patients with severe (AVA $\leq 1.0 \mathrm{~cm}^{2}$ ) and moderate (AVA 1.0 to $1.5 \mathrm{~cm}^{2}$ ) aortic stenosis according to continuity equation [4] were included. Exclusion criteria were $>$ moderate mitral or tricuspid valve disease, $>$ moderate aortic valve regurgitation, pacemaker stimulation during echocardiography, heart rate $>100 \mathrm{bpm}$, hypertrophic cardiomyopathy, bundle branch block (QRS duration $>120 \mathrm{~ms}$ ), atrial fibrillation without similar R-R cycles as well as insufficient image quality precluding strain analysis. Since high quality images of echocardiography are necessary to obtain valid strain measurements, strict exclusion criteria regarding image quality have to be applied. Hence, the number of patients per group does not represent the true prevalence of aortic stenosis subtypes. The study flow chart is shown in Fig. 1. Patients with moderate aortic stenosis served as comparison group and were consecutively included from 2015 to 2017.
Patients with severe aortic stenosis were divided into 4 groups according to the current guidelines $[3,4]$ :

- Normal-flow (stroke volume index $>35 \mathrm{ml} / \mathrm{m}^{2}$ ) and highgradient ( $\mathrm{AV}$ mean pressure gradient $\geq 40 \mathrm{mmHg}$ ) ( $=\mathrm{NF}$ HG)

- Normal-flow, low-gradient (AV mean pressure gradient $<40 \mathrm{mmHg}$ ) (=NF LG)

- Low-flow (stroke volume index $\leq 35 \mathrm{ml} / \mathrm{m}^{2}$ ), low-gradient and left ventricular ejection fraction (LVEF) $\geq 50 \%$ ( $=\mathrm{LF}$ LG EF $\geq 50 \%$ ), i.e. paradoxical low-flow, low-gradient AS

- Low-flow, low-gradient and left ventricular ejection fraction (LVEF) $<50 \%$ (=LF LG EF $<50 \%$ ), i.e. classical low-flow, low-gradient AS

The clinical parameters, i.e. heart failure symptoms, blood pressure, medication, comorbidities and ECG, were extracted from the hospital patient management data warehouse. The study was approved by the local ethics committee (No. 119/18-ek).

\section{Echocardiography}

Standard echocardiography with 2D, Doppler and tissue Doppler imaging were performed according to current standards using Vivid E9 and E95 (General Electric, Horton, Norway). Quantitative analysis was conducted offline with the EchoPac software (General Electric, Horton, Norway). LV end-diastolic and end-systolic diameter, LV mass and relative wall thickness (RWT) were determined from M-mode in the parasternal short axis view [11]. Body surface area, estimated with Dubois formula, was used for indexation of echocardiographic parameters. LV end-diastolic (LVEDVi) and end-systolic volume index (LVESVi) were calculated according to the
Fig. 1 Flow chart of the study. The figure demonstrates the extraction of patients with moderate and severe aortic stenosis from the hospital data warehouse, reasons for exclusion, and the final study population. *2015-2017 for patients with moderate aortic stenosis

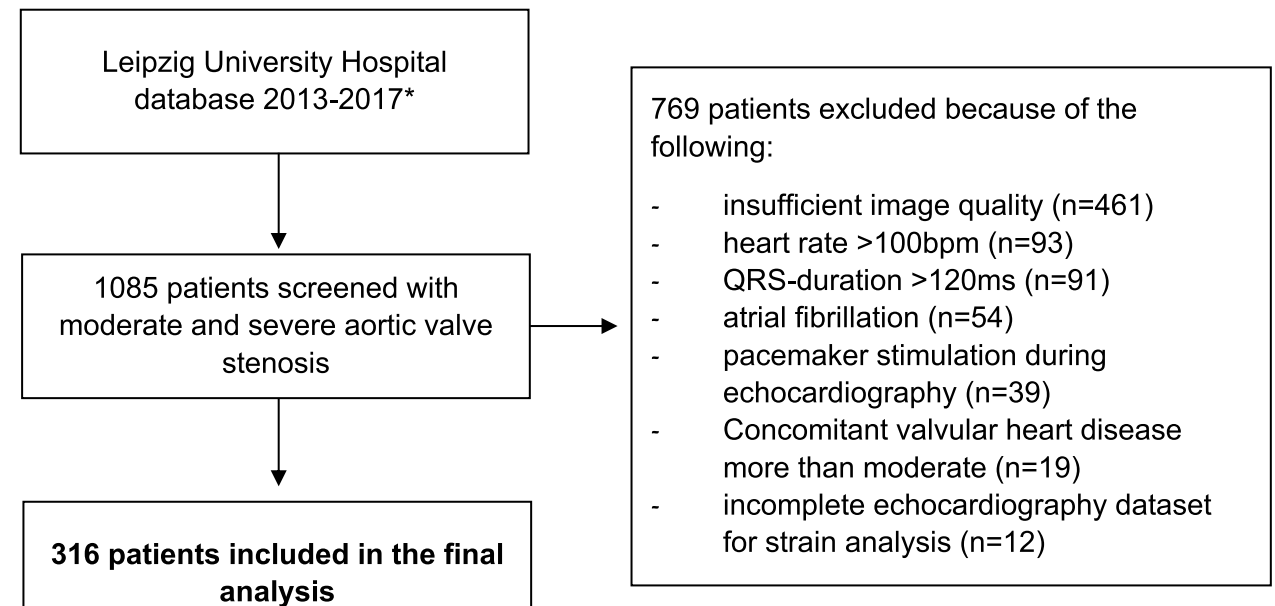

analysis 
2D biplane method of discs [11]. LVEF was calculated as (LVEDVi-LVESVi)/LVEDVi. Stroke volume index (SVi) was determined from pulsed-wave Doppler and diameter of the LV outflow tract and body surface area [4]. Cardiac index (CI) was calculated as $\mathrm{SVi} \times$ heart rate.

Peak E-wave velocity, peak A-wave velocity, and the E/A ratio was determined from pulsed-wave Doppler at the mitral valve inflow [16]. E' was measured at the septal and lateral mitral valve using tissue Doppler, and E/E' was calculated from a mean E' value [16].

$\mathrm{AV}$ peak velocity and mean AV pressure gradient were measured from continuous-wave Doppler through the aortic valve in the apical long axis view [4]. Severe aortic stenosis was confirmed by planimetry of AVA on transesophageal echocardiography or by low-dose dobutamine stress echocardiography, as appropriate [3]. The valvulo-arterial impedance (Zva), a measure of global LV afterload in aortic stenosis integrating valvular and arterial load [17], was calculated as the sum of systolic arterial blood pressure and the mean AV pressure gradient, divided by SVi. Aortic regurgitation was graded according to the recent recommendations using a multiparametric approach [18].

\section{Deformation analysis}

Global longitudinal peak systolic strain (GLS) was derived from speckle-tracking analysis of apical 4-chamber-, 2-chamber- and long-axis views according to the 17 segment LV model [11]. Systolic time interval was determined from LV outflow tract pulsed-wave Doppler. Time-to-peak strain was measured as time from $\mathrm{Q} / \mathrm{R}$ onset on ECG to peak longitudinal strain in each LV segment (Fig. 2). If more than two myocardial segments could not be analyzed (e.g. due to poor image quality or a complete lack of a negative strain curve), the patient was removed from the analysis. Mechanical dispersion was calculated as the standard deviation of time-topeak strain values in $17 \mathrm{LV}$ segments [12]. Heart rate was measured from simultaneous ECG during echocardiography on bulls-eye plot of GLS. To account for different heart rates in the study population, MD was additionally normalized to a heart rate of $60 \mathrm{bpm}$ (i.e. to a cycle length of $1000 \mathrm{~ms}$ ). This analysis was performed by calculating the normalized time-to-peak-strain values in each of the $17 \mathrm{LV}$ myocardial segments with subsequent calculation of a normalized MD value. In atrial fibrillation, strain analysis was performed in apical views with similar cycle lengths allowing GLS and MD measurements.
Fig. 2 Measurement of mechanical dispersion from longitudinal strain analysis. Time-to-peak strain (horizontal arrows) was measured in each myocardial segment derived from 2D speckle-tracking echocardiography. The yellow vertical line represents the beginning of $\mathrm{Q} / \mathrm{S}$, i.e. the systole. Mechanical dispersion was calculated as the standard deviation of time-to-peak strain in 17 myocardial segments

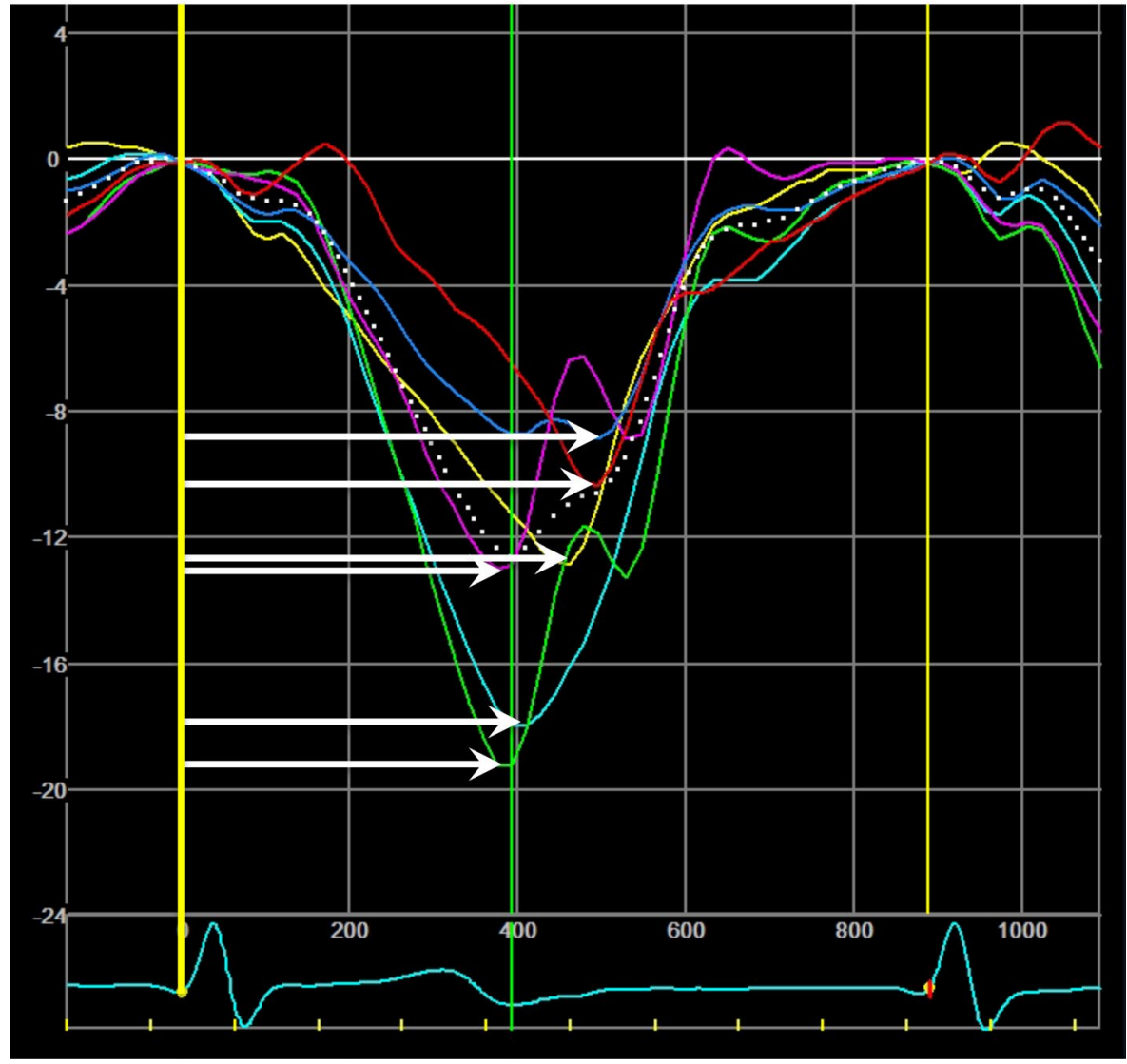




\section{Intra- and inter-observer variability}

Intra- und inter-observer variability for GLS and MD was assessed in 30 randomly selected patients. The intraobserver variability was determined by blinded re-analysis (L.K.K.) after a time period of at least 8 weeks from the initial analysis. Interobserver variability (L.K.K. vs. D.L.) was assessed by blinded analysis. The intra-observer correlation coefficient for GLS was $\mathrm{r}=0.958$ (95\% confidence interval (CI) $0.911-0.981, \mathrm{p}<0.0001$ ), mean difference $0.2 \pm 1.1 \%$ $(\mathrm{p}=0.414)$, and for MD $\mathrm{r}=0.879(95 \%$ CI $0.754-0.943$, $\mathrm{p}<0.0001)$, mean difference $0.5 \pm 5.8(\mathrm{p}=0.556)$ for MD. The inter-observer variability was for GLS $r=0.903(95 \%$ CI $0.800-0.954, \mathrm{p}<0.0001)$, mean difference $0.7 \pm 1.8 \%$ $(\mathrm{p}=0.09)$, and for MD $\mathrm{r}=0.846(95 \%$ CI $0.5692-0.926$, $\mathrm{p}<0.0001)$, mean difference $0.8 \pm 7.5(\mathrm{p}=0.543)$.

\section{Statistical analysis}

Data are presented as mean \pm standard deviation or percentages, as appropriate. One-way ANOVA test with correction for multiple comparisons (Tukey test) was applied for statistical comparisons of continuous variables between multiple groups. Categorical variables were compared using Chisquare test, providing a global $\mathrm{p}$ value.

The correlation coefficient was calculated using the Spearman method. Intra- und interobserver variability was analyzed using Spearman correlations and the Wilcoxon matched-paired test. Statistical analysis was performed with GraphPad Prism software, version 6. Statistical significance was considered with a two-sided $\mathrm{p}<0.05$.

\section{Results}

\section{Patient characteristics}

The characteristics of the 316 patients are shown in Table 1 . Age, NYHA functional class, blood pressure and cardiovascular comorbidities were similar among patients with different flow-gradient patterns of aortic stenosis. Those with LF LG EF $<50 \%$ were on similar heart failure medications than the other groups despite suffering from reduced LVEF. QRS duration was higher in patients with LF LG EF $<50 \%$ compared to the other groups of aortic stenosis.

Echocardiographic parameters of LV dimensions, LV function and aortic stenosis are presented in Table 2. NF HG was considered as the reference groups for severe aortic stenosis. Due to the subgroup definitions, AV velocity and pressure gradients, stoke volume index, LVEF and aortic valve area differed between the groups. Both patients with LF LG EF $\geq 50 \%$ and LF LG EF $<50 \%$ exhibited elevated valvulo-arterial impendance compared to the other groups.
Prevalence of concomitant moderate aortic regurgitation was $<20 \%$ in all groups. Patients with LF LG EF $\geq 50 \%$ were characterized by smaller end-diastolic LV volume but high relative wall thickness and similar GLS compared to NF HG. Patients with LF LG EF $<50 \%$ exhibited increased LV enddiastolic and end-systolic volumes with lower relative wall thickness, reduced GLS, low cardiac index despite higher heart rate, and an increased E/A ratio.

\section{Mechanical dispersion}

Left ventricular mechanical dispersion is shown in Fig. 3. Between NF HG $(49.4 \pm 14.7 \mathrm{~ms})$, NF LG $(43.5 \pm 12.9 \mathrm{~ms})$, LF LG $\mathrm{EF} \geq 50 \%(47.2 \pm 16.3 \mathrm{~ms})$ and moderate $(44.2 \pm 15.7 \mathrm{~ms}) \mathrm{AS}$, there was no difference in mechanical dispersion (Table 2). Mechanical dispersion in patients with LF LG EF $<50 \%(60.8 \pm 20.7 \mathrm{~ms})$ was increased compared to NF HG $(p=0.0177)$, NF LG $(p<0.0001)$, LF LG $\mathrm{EF} \geq 50 \%(\mathrm{p}=0.0043)$ and moderate AS ( $p<0.0001 ;$ Fig. 3$)$. Since the different heart rate between the groups may impact strain values, MD was normalized to a heart rate of $60 \mathrm{bpm}$. By this method, the results were confirmed: There were no differences of MD between NF HG (57.9 \pm 16.5$)$, NF LG $(49.9 \pm 15.9 \mathrm{~ms}), \mathrm{LF} \mathrm{LG} \mathrm{EF} \geq 50 \%(59.0 \pm 20.2 \mathrm{~ms})$ and moderate $(52.0 \pm 20.3 \mathrm{~ms})$ AS. MD of LF LG EF $<50 \%$ patients $(82.9 \pm 36.6 \mathrm{~ms})$ was increased compared to compared to NF HG, NF LG, LF LG EF $\geq 50 \%$ and moderate AS $(\mathrm{p}<0.0001$ for all) (Table 2).

\section{Association of mechanical dispersion with aortic stenosis and LV function}

To evaluate hemodynamic associations of MD, a correlation analysis with parameters of aortic stenosis, LV remodeling, LV systolic function and QRS duration was performed. In the entire cohort of patients with aortic stenosis, there was no correlation of MD with mean AV gradient, AVA index, LV mass index (Fig. 4), valvulo-arterial impedance $(r=0.0265, p=0.648$, data not shown $)$, LVEDVi $(\mathrm{r}=-0.0217, \mathrm{p}=0.7017$, data not shown), LVESVi $(\mathrm{r}=0.0393, \mathrm{p}=0.4873$, data not shown $)$, stroke volume index, LVEF or QRS duration (Fig. 4). There was a weak but significant correlation of MD with GLS and with heart rate (Fig. 4).

We performed an additional explorative correlation analysis by including patients with chronic systolic heart failure ( $\mathrm{n}=84$ consecutive patients, mean LVEF $35 \pm 7 \%$, MD 59.4 $\pm 16.7 \mathrm{~ms}$, extracted from the echocardiography database) without aortic stenosis to account for a full spectrum of LV remodeling and LV function. In this population, MD correlated significantly with LVEDVi $(r=0.1804$, $p=0.0003)$, LVESVi $(r=0.2530, p<0.0001)$, LVEF $(\mathrm{r}=-0.2895, \mathrm{p}<0.0001)$ and GLS $(\mathrm{r}=0.3108, \mathrm{P}<0.0001)$. 
Table 1 Clinical characteristics

\begin{tabular}{|c|c|c|c|c|c|c|}
\hline Clinical characteristics & $\begin{array}{l}\text { NF HG } \\
\mathrm{N}=79\end{array}$ & $\begin{array}{l}\text { NF LG } \\
N=62\end{array}$ & $\begin{array}{l}\mathrm{LF} \text { LG EF } \geq 50 \% \\
\mathrm{~N}=57\end{array}$ & $\begin{array}{l}\text { LF LG EF }<50 \% \\
N=23\end{array}$ & $\begin{array}{l}\text { Moderate } \\
\mathrm{N}=95\end{array}$ & $\mathrm{P}$ value \\
\hline Age (years) & $74.1 \pm 11.3$ & $73.9 \pm 10.9$ & $78.8 \pm 9.3^{*}$ & $76.7 \pm 9.8$ & $72.1 \pm 10.8^{\S}$ & 0.0043 \\
\hline Male sex $(\%)$ & 55.7 & 45.2 & 36.8 & 73.9 & 52.6 & 0.0262 \\
\hline $\operatorname{BMI}\left(\mathrm{kg} / \mathrm{m}^{2}\right)$ & $26.5 \pm 4.3$ & $26.2 \pm 4.0$ & $27.0 \pm 4.3$ & $25.5 \pm 3.4$ & $26.9 \pm 4.1$ & $\mathrm{~ns}$ \\
\hline NYHA functional class III/IV (\%) & 42.86 & 48.78 & 45.00 & 58.33 & 41.54 & ns \\
\hline Systolic blood pressure (mmHg) & $137.8 \pm 22.8$ & $143.6 \pm 22.0$ & $140.3 \pm 26.9$ & $138.6 \pm 23.2$ & $141.7 \pm 24.1$ & ns \\
\hline Diastolic blood pressure $(\mathrm{mmHg})$ & $78.7 \pm 15.7$ & $75.0 \pm 11.4$ & $76.2 \pm 13.9$ & $79.2 \pm 19.1$ & $77.5 \pm 13.3$ & ns \\
\hline Hypertension (\%) & 77.8 & 68.6 & 78.2 & 57.1 & 78.0 & ns \\
\hline Diabetes (\%) & 25.4 & 19.6 & 29.1 & 19.0 & 31.7 & ns \\
\hline Dyslipidemia (\%) & 55.6 & 56.9 & 54.5 & 57.1 & 56.1 & ns \\
\hline Coronary artery disease $(\%)$ & 41.3 & 33.3 & 30.9 & 38.1 & 30.5 & ns \\
\hline Previous myocardial infarction (\%) & 7.9 & 9.8 & 5.5 & 23.8 & 14.6 & ns \\
\hline Previous PCI (\%) & 7.9 & 25.5 & 12.7 & 14.3 & 18.3 & ns \\
\hline Previous CABG (\%) & 4.8 & 5.9 & 5.5 & 4.8 & 2.4 & ns \\
\hline Renal impairment (\%) & 32.8 & 21.2 & 50.9 & 57.1 & 30.1 & ns \\
\hline $\operatorname{GFR}\left(\mathrm{ml} / \mathrm{min} / 1.73 \mathrm{~m}^{2}\right)$ & $66.8 \pm 21.3$ & $70.3 \pm 19.3^{\S}$ & $58.1 \pm 22.8^{\dagger}$ & $58.6 \pm 25.8$ & $66.5 \pm 4.8$ & 0.0398 \\
\hline Beta blocker (\%) & 50.0 & 59.6 & 72.7 & 57.1 & 60.0 & ns \\
\hline Calcium channel blocker (\%) & 31.3 & 36.5 & 25.5 & 19.0 & 35.0 & ns \\
\hline ACE-I/ARB/ARNI (\%) & 73.4 & 69.2 & 76.4 & 47.6 & 76.3 & ns \\
\hline MR antagonists (\%) & 3.1 & 3.8 & 7.3 & 19.0 & 3.8 & ns \\
\hline Diuretics (\%) & 42.2 & 34.6 & 63.6 & 61.9 & 43.8 & 0.0165 \\
\hline Other antihypertensives (\%) & 6.3 & 11.5 & 14.5 & 14.3 & 8.8 & ns \\
\hline Ivabradine (\%) & 0 & 3.8 & 0 & 0 & 0 & 0.0742 \\
\hline Antiarrhythmics (\%) & 3.1 & 1.9 & 1.8 & 0 & 0 & ns \\
\hline Digitoxin (\%) & 4.7 & 1.9 & 3.6 & 4.8 & 6.3 & ns \\
\hline QRS duration (ms) & $88.1 \pm 12.9$ & $86.5 \pm 12.9^{\prime \prime}$ & $84.2 \pm 15.2^{\|}$ & $101.8 \pm 13.4^{* \dagger 末 \S}$ & $87.1 \pm 11.5^{\prime \prime}$ & 0.0009 \\
\hline Atrial fibrillation (\%) & 17.5 & 19.6 & 45.5 & 19.0 & 28.0 & 0.0056 \\
\hline
\end{tabular}

Since normal-flow (NF; stroke volume index $>35 \mathrm{ml} / \mathrm{m}^{2}$ ), high-gradient (HG; AV mean pressure gradient $\geq 40 \mathrm{mmHg}$ ) was considered as reference group of aortic stenosis, statistical symbols were not displayed the NF HG column. Renal impairment was defined as estimated glomerular filtration rate $(\mathrm{eGFR})<60 \mathrm{ml} / \mathrm{min} / 1.73 \mathrm{~m}^{2}$. ACE-I, angiotensin converting enzyme inhibitor; ARB, angiotensin II receptor type 1 blocker; ARNI, angiotensin receptor neprilysin inhibitor; BMI, body mass index; CABG, coronary artery bypass graft; EF, ejection fraction; LF, lowflow (stroke volume index $\leq 35 \mathrm{ml} / \mathrm{m}^{2}$ ); LG, low-gradient (AV mean pressure gradient $<40 \mathrm{mmHg}$ ); $\mathrm{MR}$, mineralocorticoid receptor; PCI=percutaneous coronary intervention. ${ }^{*} \mathrm{p}<0.05$ vs. moderate aortic stenosis (AS); $\uparrow \mathrm{p}<0.05$ vs. NF LG; $\ddagger \mathrm{p}<0.05 \mathrm{vs}$. NF HG; $\S \mathrm{p}<0.05$ vs. LF LG $\mathrm{EF} \geq 50 \% ; \| \mathrm{p}<0.05$ vs. LF LG $\mathrm{EF}<50 \%$

\section{Discussion}

Our study demonstrates that mechanical dispersion is similar among flow-gradient subgroups of severe aortic stenosis with preserved LVEF. Patients with low-flow, low-gradient aortic stenosis and reduced LVEF $(<50 \%)$ showed increased mechanical dispersion, i.e. intraventricular dyssynchrony despite having a narrow QRS complex. These data indicate that mechanical dispersion is marker of LV systolic dysfunction, rather than a distinct characteristic of aortic stenosis.

Since severe aortic stenosis is a heterogenous entity, concise hemodynamic characterization is of particular importance. We considered normal-flow high-gradient (NF HG) as the reference group because these patients fulfill all criteria for severe aortic stenosis [3, 4]. Patients with normal-flow, low-gradient (NF LG) represent an intermediate stage between moderate and NF HG severe aortic stenosis [6, 19], reflected by intermediate values of LV mass, relative wall thickness, valve area, and AV gradients in our study. Paradoxical low-flow low-gradient (LF LG EF $\geq 50 \%$ ) aortic stenosis patients are characterized by advanced concentric LV hypertrophy with high relative wall thickness, high valvulo-arterial load, small LV volumes and thus reduced stroke volume despite preserved LVEF [6, 19, 20]. Patients with classical low-flow low-gradient (LF LG EF $<50 \%)$ are characterized by eccentric LV hypertrophy and impaired systolic LV function, i.e. reduced LVEF, GLS, stroke volume and cardiac index. In addition, classical LF LG patients had advanced diastolic dysfunction indices, increased heart rate and high valvulo-arterial load. Thus, patients classical LF 
Table 2 Echocardiographic data

\begin{tabular}{|c|c|c|c|c|c|c|}
\hline & $\begin{array}{l}\text { NF HG } \\
\mathrm{N}=79\end{array}$ & $\begin{array}{l}N F \text { LG } \\
N=62\end{array}$ & $\begin{array}{l}\text { LF LG EF } \geq 50 \% \\
N=57\end{array}$ & $\begin{array}{l}\text { LF LG EF }<50 \% \\
N=23\end{array}$ & $\begin{array}{l}\text { Moderate } \\
\mathrm{N}=95\end{array}$ & $P$ value \\
\hline Heart rate $(\mathrm{HR})(\mathrm{bpm})$ & $71.5 \pm 12.0$ & $69.2 \pm 10.6^{\S \|}$ & $76.1 \pm 11.9^{\dagger}$ & $79.5 \pm 14.7^{* \dagger}$ & $70.8 \pm 11.1^{\prime \prime}$ & 0.0004 \\
\hline LV end-diastolic diameter (mm) & $44.9 \pm 6.1$ & $43.5 \pm 5.7^{\prime \prime}$ & $42.6 \pm 7.3^{\prime \prime}$ & $52.5 \pm 8.3 * \dagger \S$ & $45.3 \pm 6.7^{\| 1}$ & $<0.0001$ \\
\hline LV end-systolic diameter (mm) & $28.9 \pm 4.9$ & $27.0 \pm 5.6^{11}$ & $27.4 \pm 6.7^{\prime \prime}$ & $41.0 \pm 7.5^{* \dagger \ddagger \S}$ & $29.2 \pm 6.0^{11}$ & $<0.0001$ \\
\hline LV mass index $\left(\mathrm{g} / \mathrm{m}^{2}\right)$ & $160.8 \pm 46.3$ & $134.0 \pm 31.8^{\ddagger \|}$ & $130.2 \pm 36.5^{\ddagger \|}$ & $172.1 \pm 51.9^{* \dagger \S}$ & $127.8 \pm 44.7^{\text {†॥ }}$ & $<0.0001$ \\
\hline RWT & $0.68 \pm 0.15$ & $0.65 \pm 0.15$ & $0.69 \pm 0.20 * \|$ & $0.56 \pm 0.18^{\ddagger \S}$ & $0.58 \pm 0.16^{\ddagger \S}$ & $<0.0001$ \\
\hline $\mathrm{LV}$ end-diastolic volume index $\left(\mathrm{ml} / \mathrm{m}^{2}\right)$ & $58.1 \pm 18.0$ & $49.4 \pm 12.1^{\text {‡॥ }}$ & $48.0 \pm 15.1^{\text {†ㅔ }}$ & $75.7 \pm 27.5^{* \dagger \S}$ & $54.2 \pm 15.8^{\| \prime}$ & $<0.0001$ \\
\hline LV end-systolic volume index $\left(\mathrm{ml} / \mathrm{m}^{2}\right)$ & $22.4 \pm 10.5$ & $18.3 \pm 6.6^{\| \prime}$ & $20.1 \pm 8.1^{\| \prime}$ & $50.0 \pm 19.65^{* \dagger \ddagger}$ & $20.3 \pm 8.3^{\prime \prime}$ & $<0.0001$ \\
\hline LV EF $(\%)$ & $62.7 \pm 7.8$ & $63.5 \pm 7.2^{11}$ & $59.1 \pm 7.1 *+11$ & $33.5 \pm 8.3 * \dagger \S$ & $63.0 \pm 7.8^{8 \|}$ & $<0.0001$ \\
\hline Stroke volume index $\left(\mathrm{ml} / \mathrm{m}^{2}\right)$ & $44.9 \pm 6.4$ & $43.6 \pm 6.1^{\S \|}$ & $28.5 \pm 4.4 * \hbar+$ & $26.5 \pm 6.0 * \dagger+$ & $42.8 \pm 11.2^{\S \|}$ & $<0.0001$ \\
\hline Cardiac index $\left(1 / \mathrm{min} / \mathrm{m}^{2}\right)$ & $3.2 \pm 0.6$ & $3.0 \pm 0.6^{\S \|}$ & $2.2 \pm 0.4 * \dagger$ & $2.0 \pm 0.4 * *$ & $3.0 \pm 08^{\S \|}$ & $<0.0001$ \\
\hline $\mathrm{E} / \mathrm{A}$ & $0.9 \pm 0.5$ & $1.0 \pm 0.7^{\|}$ & $1.0 \pm 0.8^{\|}$ & $1.6 \pm 1.2 * \dagger \$ \S$ & $1.0 \pm 0.4^{\| \prime}$ & 0.0128 \\
\hline $\mathrm{E} / \mathrm{E}^{\prime}$ & $18.6 \pm 7.4$ & $17.9 \pm 9.3$ & $17.9 \pm 8.2$ & $20.9 \pm 7.7$ & $15.8 \pm 7.2$ & ns \\
\hline Peak aortic valve jet velocity $(\mathrm{m} / \mathrm{s})$ & $4.9 \pm 0.6$ & $3.7 \pm 0.4 * \$ \S \|$ & $3.3 \pm 0.6^{\dagger+}$ & $3.2 \pm 0.6^{\dagger \neq}$ & $3.1 \pm 0.8^{\dagger \dagger}$ & $<0.0001$ \\
\hline Mean aortic valve gradient $(\mathrm{mmHg})$ & $56.8 \pm 14.6$ & $30.2 \pm 5.9 *$ *\# & $25.9 \pm 8.0^{\ddagger}$ & $22.6 \pm 8.6^{\dagger \neq}$ & $23.0 \pm 12.3^{\dagger \neq}$ & $<0.0001$ \\
\hline Valvulo-arterial impedance $\left(\mathrm{mmHg} / \mathrm{ml} / \mathrm{m}^{2}\right)$ & $4.4 \pm 0.8$ & $4.1 \pm 0.8^{\S \|}$ & $6.0 \pm 1.4^{* \dagger}$ & $6.8 \pm 3.5^{* \dagger+}$ & $4.1 \pm 1.2^{\S \|}$ & $<0.0001$ \\
\hline Aortic valve area $\left(\mathrm{cm}^{2}\right)$ & $0.71 \pm 0.14$ & $0.9 \pm 0.17 * \sharp \S \|$ & $0.75 \pm 0.12 * \dagger$ & $0.74 \pm 0.19^{* \dagger}$ & $1.2 \pm 0.19^{\dagger \ddagger \S \|}$ & $<0.0001$ \\
\hline Aortic valve area index $\left(\mathrm{cm}^{2} / \mathrm{m}^{2}\right)$ & $0.39 \pm 0.08$ & $0.5 \pm 0.08 * \ddagger \S \|$ & $0.42 \pm 0.07 * \dagger$ & $0.41 \pm 0.1 *^{\dagger}$ & $0.65 \pm 0.12^{\dagger \neq \S ॥}$ & $<0.0001$ \\
\hline Moderate aortic regurgitation $(\%)$ & 19.0 & 8.1 & 14.0 & 13.0 & 10.5 & ns \\
\hline GLS $(\%)$ & $-18.6 \pm 3.8$ & $-19.9 \pm 2.8^{\S \|}$ & $-16.9 \pm 3.4 *+\div \|$ & $-8.6 \pm 3.7 * \dagger \neq \S$ & $-19.0 \pm 3.9^{\S \|}$ & $<0.0001$ \\
\hline Mechanical dispersion (ms) & $49.4 \pm 14.7$ & $43.5 \pm 12.9^{\| \prime}$ & $47.2 \pm 16.3^{\|}$ & $60.8 \pm 20.7 * \dagger \$$ & $44.2 \pm 15.7^{\| 1}$ & $<0.0001$ \\
\hline $\begin{array}{l}\text { Mechanical dispersion normalized to } 60 \mathrm{bpm} \\
(\mathrm{ms})\end{array}$ & $57.9 \pm 16.5$ & $49.9 \pm 15.9^{\|}$ & $59.0 \pm 20.2^{\|}$ & $82.9 \pm 36.6^{* \dagger \$ 8}$ & $52.0 \pm 20.3^{\| \prime}$ & $<0.0001$ \\
\hline
\end{tabular}

Since NF HG was considered as reference group of aortic stenosis, statistical symbols were not displayed for this group. GLS global longitudinal strain, $L V$ left ventricular, $R W T$ relative wall thickness; other abbreviations as in Table $1 .{ }^{*} \mathrm{p}<0.05$ vs. moderate aortic stenosis (AS); ${ }^{\dagger} \mathrm{p}<0.05$ vs. NF LG; ${ }^{\ddagger}$ p $<0.05$ vs. NF HG; ${ }^{\S} \mathrm{p}<0.05$ vs. LF LG EF $\geq 50 \%$; $"$ p $<0.05$ vs. LF LG EF $<50 \%$

LG represent with a complex hemodynamic situation of systolic heart failure with an additional afterload burden due to severe aortic stenosis.

Mechanical dispersion (MD) is derived from LV longitudinal strain analysis and represents intraventricular dyssynchrony of contraction [12,14, 21,22]. Our data show that in patients with severe aortic stenosis and preserved LVEF, mechanical dispersion was similar whether flow was low or normal. In particular, patients with paradoxical LF LG aortic stenosis do not exhibit subclinical LV dyssynchrony despite their low-flow situation. These data indicate that mechanical dispersion is not a hemodynamic determinant of lowflow state per se in aortic stenosis if LVEF is preserved. In contrast, increased mechanical dispersion in patients with dilated left ventricles and impaired systolic LV function, i.e. classical LF LG aortic stenosis, indicates that these patients suffer from LV dyssynchrony even in the absence of a bundle branch block. These data indicate that LV dyssynchrony seems to be insufficiently represented in the surface ECG, setting the stage for incremental value of MD in patients with narrow QRS complex. Patients with bundle branch block, i.e. QRS duration $>120 \mathrm{~ms}$, were excluded from the analysis because they have obvious LV dyssynchrony [15].
Myocardial fibrosis is one of several underlying factors of increased MD [21]. A recent study found increased myocardial fibrosis in patients with classical LF LG aortic stenosis compared to patients with HG aortic stenosis with preserved LVEF, which might represent the morphological substrate for increased MD in this group [23]. Furthermore, heart rate may impact values of mechanical dispersion, which should be taken into account when comparing strain measurements. Correlation analysis revealed no associations between MD and parameters of aortic stenosis severity in our study. Prihadi et al. reported a correlation of MD with LV mass, aortic valve area, age, LVEF and QRS duration [13]. These discrepancies might be attributable to dissimilar study populations with up to $50 \%$ of patients with bundle branch block or intraventricular conduction abnormalities in the aforementioned study [13]. Taken together, bundle branch block occurs frequently in severe AS and is a cause for increased MD. Subclinical LV dyssynchrony in patients with severe AS and narrow QRS complex seems to be related to the underlying LV dysfunction rather than to valvular load due to aortic stenosis. These data are supported by an exploratory analysis including patients with chronic systolic heart failure without aortic stenosis showing 
Fig. 3 Summary figure of mechanical dispersion in aortic stenosis. a quantitative comparison of mechanical dispersion in subgroups of aortic stenosis. b representative LV bulls-eye plots with color-coded timeto-peak strain values for each myocardial segment. $E F$ ejection fraction, $H G$ high-gradient (AV mean pressure gradient $\geq 40 \mathrm{mmHg}$ ), $L F$ low-flow (stroke volume index $\leq 35 \mathrm{ml} /$ $\mathrm{m}^{2}$ ), $L G$ low-gradient (AV mean pressure gradient $<40 \mathrm{mmHg}$ ), $N F$ normal-flow (stroke volume index $>35 \mathrm{ml} / \mathrm{m}^{2}$ ). *p $<0.0001$ vs. moderate aortic stenosis; ${ }^{\dagger} \mathrm{p}<0.0001$ vs. NF LG; ${ }^{\ddagger} \mathrm{p}<0.05$ vs. NF HG; ${ }^{\S} \mathrm{p}<0.01$ vs. $\mathrm{LF}$ LG $\mathrm{EF} \geq 50 \%$

\section{Mechanical dispersion in aortic stenosis}

A
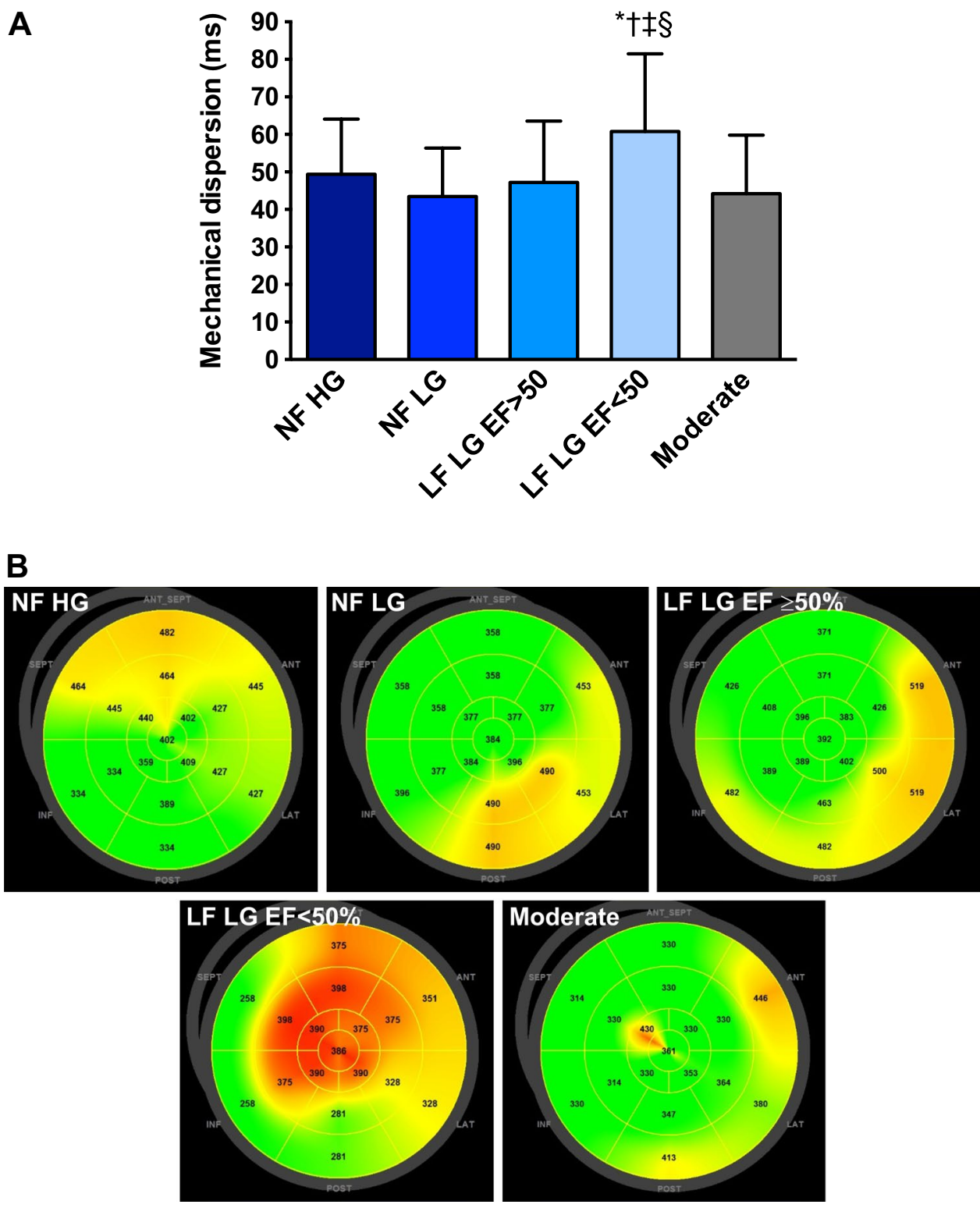

significant associations between MD and parameters of LV remodeling and LV dysfunction. However, these hypothesisgenerating findings have to be confirmed in further studies.

MD is a robust parameter as shown by good inter- and intra-observer variability in our analysis and by others [12, 24]. MD has been identified as a marker for the occurrence of ventricular arrhythmias in numerous cardiac diseases [14], such as after myocardial infarction [12, 22] and in hypertrophic cardiomyopathy [21]. Klaeboe et al. demonstrated a prognostic implication of MD for predicting all-cause mortality in patients with severe aortic stenosis, which was incremental to LVEF, GLS and valvulo-arterial impedance [24]. A recent retrospective analysis in patients with various degrees of aortic stenosis confirmed the prognostic value of MD for all-cause mortality and reported that MD increases with the severity of disease [13]. However, these studies did not analyze mechanical dispersion in the subgroups of aortic stenosis according to flow and gradient $[3,6]$. Our analysis characterized MD in subtypes of aortic stenosis with narrow QRS complex according to flow, gradient and LVEF. The data argue against a subclinical LV dyssynchrony based on MD measurement in patients with severe AS in both normal-flow and low-flow states as long as LVEF is preserved. Those with LF LG 
Fig. 4 Correlations of mechanical dispersion. Mechanical dispersion (MD) and a mean aortic valve (AV) gradient, $\mathbf{b}$ aortic valve area (AVA) index, $\mathbf{c}$ stroke volume index (SVi), $\mathbf{d}$ LV mass index, e LV ejection fraction (EF), f longitudinal systolic strain (GLS), $\mathbf{g}$ heart rate, and $\mathbf{h}$ QRS duration. Linear regression lines, correlation coefficients (r) and $\mathrm{p}$ values are presented in the figure
A

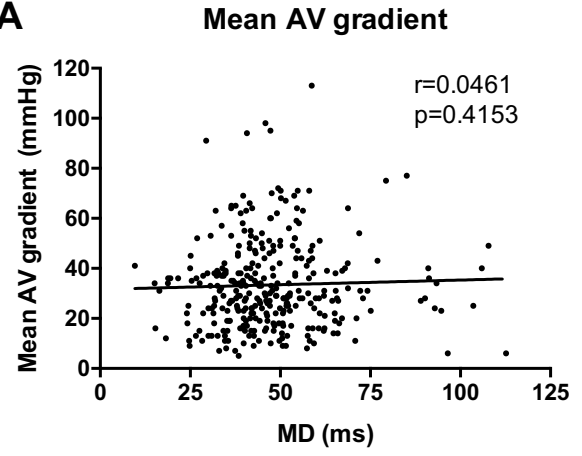

C

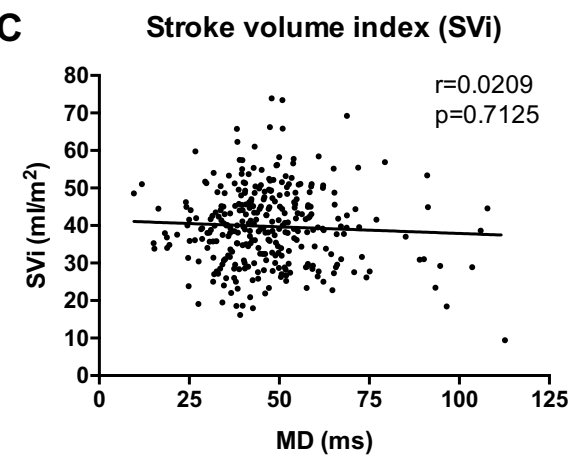

E

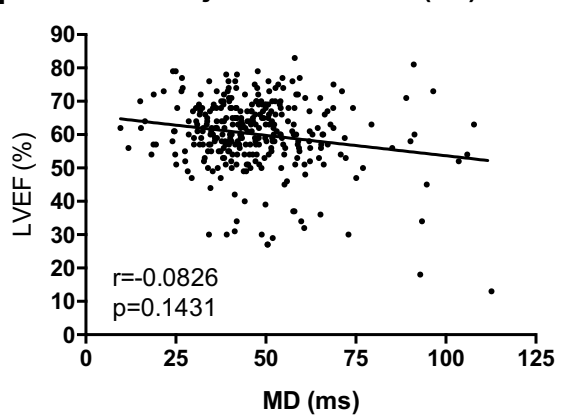

G

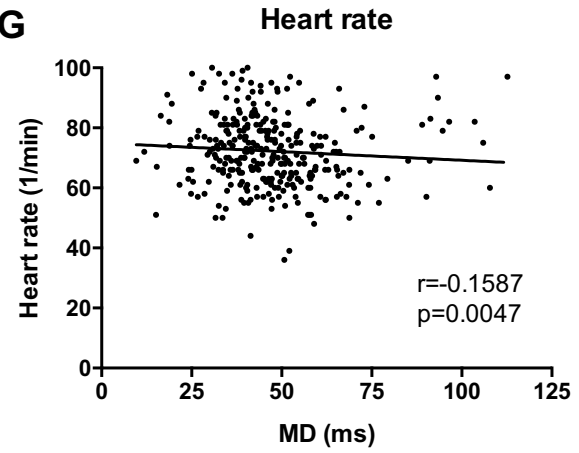

B

Aortic valve area (AVA) index

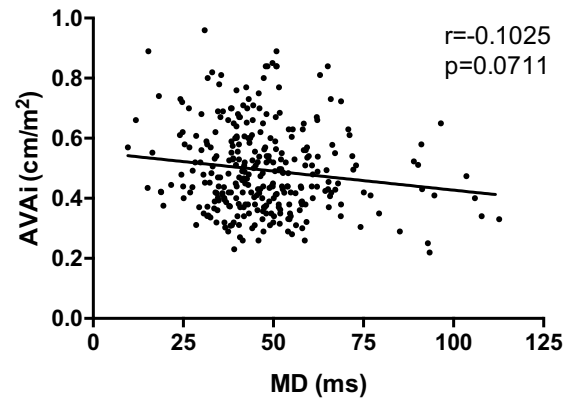

D

LV mass index

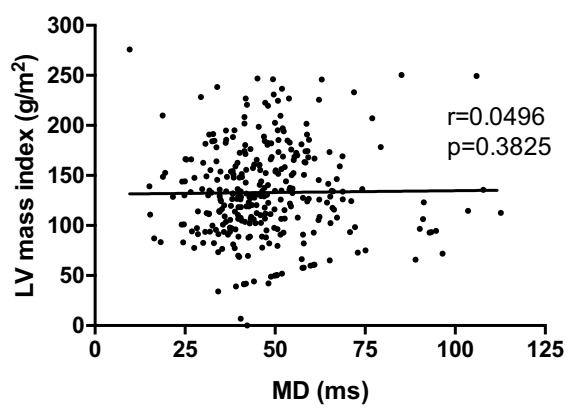

$\mathbf{F}$

Global longitudinal strain (GLS)

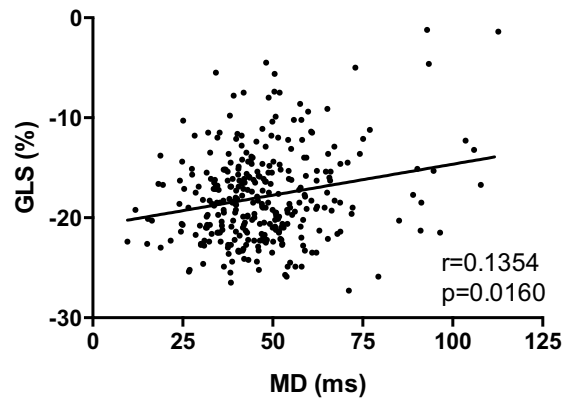

H

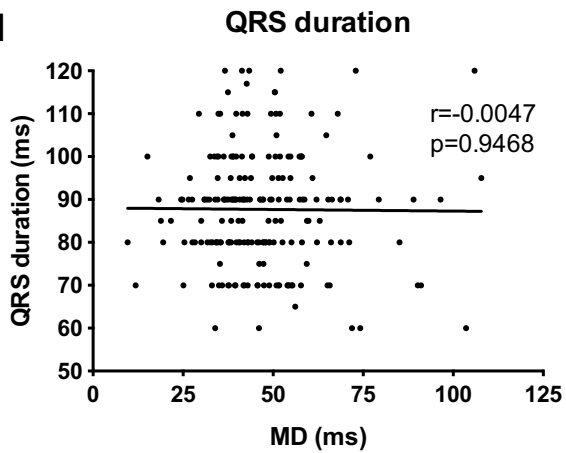

and reduced LVEF had increased mechanical dispersion indicating LV dyssynchrony. This finding support the well-established prognostic impact of MD because these patients had the worst prognosis in the literature [6]. 


\section{Limitations}

This is a retrospective analysis with its inherent limitations. NYHA function class assessment might have poor accuracy due to the lack of complete and systematic data acquisition. The aim of this mechanistic study was to evaluate the hemodynamic associations of MD in patients with aortic stenosis. Therefore, prognostic implications of MD were beyond the scope of our study. Whether MD provides incremental prognostic information in aortic stenosis subgroups has to be evaluated by further prospective studies. There are several reasons for reduced LVEF in patients with classical LF LG aortic stenosis and in those with chronic heart failure, hence a causal association with MD cannot be proven based on these data.

\section{Conclusion}

In patients with severe aortic stenosis and narrow QRS complex, mechanical dispersion was similar in low-flow and normal-flow subgroups if LVEF was preserved. Patients with low-flow low-gradient aortic stenosis and reduced LVEF had increased mechanical dispersion, i.e. pronounced intraventricular dyssynchrony. These data indicate that mechanical dispersion is rather a marker of systolic myocardial dysfunction than of aortic stenosis.

Acknowledgements Open Access funding provided by Projekt DEAL.

Author contributions All authors contributed to the study conception and design. Material preparation, data collection and analysis were performed by DL, LKK, JK and SS. The first draft of the manuscript was written by DL and all authors commented on previous versions of the manuscript. All authors read and approved the final manuscript.

Funding This research did not receive any specific grant.

\section{Compliance with ethical standards}

Conflict of interest All authors declare that they have no conflict of interest.

Ethical approval All procedures performed in studies involving human participants were in accordance with the ethical standards of the institutional research committee (local ethics committee, No. 119/18-ek) and with the 1964 Helsinki declaration and its later amendments or comparable ethical standards.

Open Access This article is licensed under a Creative Commons Attribution 4.0 International License, which permits use, sharing, adaptation, distribution and reproduction in any medium or format, as long as you give appropriate credit to the original author(s) and the source, provide a link to the Creative Commons licence, and indicate if changes were made. The images or other third party material in this article are included in the article's Creative Commons licence, unless indicated otherwise in a credit line to the material. If material is not included in the article's Creative Commons licence and your intended use is not permitted by statutory regulation or exceeds the permitted use, you will need to obtain permission directly from the copyright holder. To view a copy of this licence, visit http://creativecommons.org/licenses/by/4.0/.

\section{References}

1. Nkomo VT, Gardin JM, Skelton TN et al (2006) Burden of valvular heart diseases: a population-based study. Lancet 368:1005-1011. https://doi.org/10.1016/S0140-6736(06)69208 $-8$

2. Carabello B, Paulus W (2009) Aortic stenosis. Lancet 373:956966. https://doi.org/10.1016/S0140-6736(09)60211-7

3. Baumgartner H, Falk V, Bax JJ et al (2017) 2017 ESC/EACTS guidelines for the management of valvular heart disease. The task force for the management of valvular heart disease. Eur Heart $\mathbf{J}$ 38:2739-2791. https://doi.org/10.1093/eurheartj/ehx391

4. Baumgartner H, Hung J, Bermejo J et al (2017) Recommendations on the echocardiographic assessment of aortic valve stenosis: a focused update from the European Association of Cardiovascular Imaging and the American Society of Echocardiography. J Am Soc Echocardiogr 30:372-392. https://doi.org/10.1016/j. echo.2017.02.009

5. Eleid MF, Sorajja P, Michelena HI et al (2013) Flow-gradient patterns in severe aortic stenosis with preserved ejection fraction: clinical characteristics and predictors of survival. Circulation 128:1781-1789. https://doi.org/10.1161/CIRCULATIO NAHA.113.003695

6. Clavel M, Magne J, Pibarot P (2016) Low-gradient aortic stenosis. Eur Hear J 37:2645-2657. https://doi.org/10.1093/eurheartj/ ehw096

7. Clavel MA, Berthelot-Richer M, Le Ven F et al (2015) Impact of classic and paradoxical low flow on survival after aortic valve replacement for severe aortic stenosis. J Am Coll Cardiol 65:645653. https://doi.org/10.1016/j.jacc.2014.11.047

8. Lancellotti P, Magne J, Donal E et al (2012) Clinical outcome in asymptomatic severe aortic stenosis: insights from the new proposed aortic stenosis grading classification. J Am Coll Cardiol 59:235-243. https://doi.org/10.1016/j.jacc.2011.08.072

9. Adda J, Mielot C, Giorgi R et al (2012) Low-Flow, low-gradient severe aortic stenosis despite normal ejection fraction is associated with severe left ventricular dysfunction as assessed by speckletracking echocardiography a multicenter study. Circ Cardiovasc Imaging. https://doi.org/10.1161/CIRCIMAGING.111.967554

10. Cikes M, Solomon SD (2016) Beyond ejection fraction: an integrative approach for assessment of cardiac structure and function in heart failure. Eur Heart J 37:1642-1650. https://doi. org/10.1093/eurheartj/ehv510

11. Lang RM, Badano LP, Mor-Avi V et al (2015) Recommendations for cardiac chamber quantification by echocardiography in adults: an update from the American Society of Echocardiography and the European Association of Cardiovascular Imaging. J Am Soc Echocardiogr 28:1-39. https://doi.org/10.1093/ehjci/jev014

12. Haugaa KH, Smedsrud MK, Steen T et al (2010) Mechanical dispersion assessed by myocardial strain in patients after myocardial infarction for risk prediction of ventricular arrhythmia. JACC Cardiovasc Imaging 3:247-256. https://doi.org/10.1016/j. jcmg.2009.11.012

13. Prihadi EA, Vollema EM, Ng ACT et al (2019) Determinants and prognostic implications of left ventricular mechanical dispersion in aortic stenosis. Eur Heart J Cardiovasc Imaging 20:740-748. https://doi.org/10.1093/ehjci/jez004 
14. Kawakami H, Nerlekar N, Haugaa KH et al (2019) Prediction of ventricular arrhythmias with left ventricular mechanical dispersion: a systematic review and meta-analysis. JACC Cardiovasc Imaging. https://doi.org/10.1016/j.jcmg.2019.03.025

15. Risum N, Bhupendar A, Hansen TF et al (2015) Identification of typical left bundle branch block contraction by strain echocardiography is additive to electrocardiography in prediction of longterm outcome after cardiac resynchronization therapy. J Am Coll Cardiol 66:631-641. https://doi.org/10.1016/j.jacc.2015.06.020

16. Nagueh SF, Smiseth OA, Appleton CP et al (2016) Recommendations for the evaluation of left ventricular diastolic function by echocardiography: an update from the American Society of Echocardiography and the European Association of Cardiovascular Imaging. J Am Soc Echocardiogr 29:277-314. https://doi. org/10.1093/ehjci/jew082

17. Briand M, Dumesnil JG, Kadem L et al (2005) Reduced systemic arterial compliance impacts significantly on left ventricular afterload and function in aortic stenosis: implications for diagnosis and treatment. J Am Coll Cardiol 46:291-298. https://doi. org/10.1016/j.jacc.2004.10.081

18. Zoghbi WA, Adams D, Bonow RO et al (2017) Recommendations for noninvasive evaluation of native valvular regurgitation: a report from the American Society of Echocardiography developed in collaboration with the Society for Cardiovascular Magnetic Resonance. J Am Soc Echocardiogr 30:303-371. https://doi. org/10.1016/j.echo.2017.01.007

19. Mehrotra P, Jansen K, Flynn AW et al (2013) Differential left ventricular remodelling and longitudinal function distinguishes low flow from normal-flow preserved ejection fraction low-gradient severe aortic stenosis. Eur Heart J 34:1906-1914. https://doi. org/10.1093/eurheartj/eht094
20. Clavel MA, Dumesnil JG, Capoulade R et al (2012) Outcome of patients with aortic stenosis, small valve area, and low-flow, low-gradient despite preserved left ventricular ejection fraction. J Am Coll Cardiol 60:1259-1267. https://doi.org/10.1016/j. jacc.2011.12.054

21. Haland TF, Almaas VM, Hasselberg NE et al (2016) Strain echocardiography is related to fibrosis and ventricular arrhythmias in hypertrophic cardiomyopathy. Eur Heart J Cardiovasc Imaging 17:613-621. https://doi.org/10.1093/ehjci/jew005

22. Haugaa KH, Grenne BL, Eek CH et al (2013) Strain echocardiography improves risk prediction of ventricular arrhythmias after myocardial infarction. JACC Cardiovasc Imaging 6:841-850. https://doi.org/10.1016/j.jcmg.2013.03.005

23. Rosa VEE, Ribeiro HB, Sampaio RO et al (2019) Myocardial fibrosis in classical low-flow, low-gradient aortic stenosis. Circ Cardiovasc Imaging 12:e008353. https://doi.org/10.1161/CIRCI MAGING.118.008353

24. Klaeboe LG, Haland TF, Leren ISL et al (2017) Prognostic value of left ventricular deformation parameters in patients with severe aortic stenosis: a pilot study of the usefulness of strain echocardiography. J Am Soc Echocardiogr 30:727-735. https://doi. org/10.1016/j.echo.2017.04.009

Publisher's Note Springer Nature remains neutral with regard to jurisdictional claims in published maps and institutional affiliations. 